\title{
Volumising value: value-based healthcare and its coming of age ${ }^{\dagger}$
}

\author{
Paul Wallang $($ )
}

\begin{abstract}
SUMMARY
Value-based healthcare holds great potential to transform healthcare globally. This commentary reviews the historical milestones in its evolution and raises critical questions regarding how it should proceed.
\end{abstract}

\section{KEYWORDS}

Value; outcomes; quality.

'Nothing is more useful than water, but it will purchase scarce anything, scarce anything can be had in exchange for it. A diamond, on the contrary, has scarce any value in use, but a very great quantity of other goods may frequently be had in exchange for it.' Adam Smith, The Wealth of Nations, 1776

The concept of 'value', as highlighted above in the quotation by the enlightenment thinker Adam Smith, has the pristine quality beloved of philosophers. A delicious paradox to ponder. For centuries the idea of 'value' has proven a wickedly hard concept to define. It continues to provide an enduring but intriguing challenge today.

Much has been written recently regarding 'valuebased healthcare'. However, the principle of collecting robust data to improve care and allocate resources has an illustrious history. Many brilliant clinicians, economists, philosophers, epidemiologists and others have understood the transformative power of using a 'value lens', with the most recent compelling articulation within healthcare posited by Michael Porter and Elizabeth Teisberg in America and Muir Gray in Europe.

As John of Salisbury wisely pointed out in his Metalogicon of 1159 (paraphrasing Bernard of Chartres): 'We see more and farther than our predecessors, not because we have keener vision or greater height, but because we are lifted up and borne aloft on their gigantic stature' (McGarry 2015: 167). Humility is a virtue, and Salisbury reminds us of our intellectual debts. Value-based healthcare at its core is a simple and long-standing formula. It prescribes ruthlessly pursuing those outcomes that are most meaningful to patients. Once those outcome domains are established, the requisite 'resources' of the organisation or national institution are focused and cultivated through learning to attain sustained improvements in those domains. More data are collected, and the virtuous cycle ensues.

\section{Florence Nightingale: statistician and outcomes innovator}

One of the earliest protagonists, who has helped the current ideas to be 'borne aloft', was Florence Nightingale. A remarkable statistician and outcomes innovator, while working at the Scutari Hospital (in modern-day Turkey) during the Crimean War (1853-1856) Nightingale systematically recorded the outcomes of care and instituted robust clinical changes based on these data. She reported that there were five main causes of death at the Scutari Hospital in 1855: 'overcrowding, problems with ventilation, poor drainage, abysmal cleanliness and lack of comfort' (Neuhauser 2003). She used these insights and outcomes data to make drastic changes to care:

\begin{abstract}
'To measure overcrowding [Nightingale] documented the amount of space per patient in London hospitals at about 1600 square feet compared with 300-500 square feet at Scutari. Windows were opened for the first time and drains were cleaned out. For example, in the week of 14 April 1855, 215 handcarts of filth were removed, the sewers were flushed 19 times and the carcasses of two horses, a cow and four dogs were buried. The soldiers brought their blankets from the Crimea "unavoidably covered with vermin". Nightingale counted the thousands of items of clothing washed. Hospital comforts included a lack of eating utensils which she supplied.' (Neuhauser 2003)
\end{abstract}

Nightingale scrupulously recorded the outcomes of care. The death rate at the Scutari Hospital plummeted from $42.7 \%$ in February 1855 to $2.2 \%$ in June 1855. A triumph for outcomes measurement.

\section{Value-based healthcare in mental health services}

Nightingale would most likely appreciate that mental healthcare creates a unique opportunity for value-based approaches, as discussed by Baggaley (2020, this issue). There are few comprehensive studies and little consensus regarding how such a framework ought to be implemented. Initial consideration has focused on diagnosis-specific outcome
Paul Wallang is Clinical Director and Lead for Outcomes and ValueBased Healthcare at St Andrews Healthcare. He is also an honorary senior research associate at University College London, UK. Correspondence Dr Paul Wallang. Email: pmwallang@standrew.co.uk

First received 25 Mar 2020 Final revision 6 Apr 2020 Accepted 13 Apr 2020

Copyright and usage (C) The Author 2020

${ }^{\dagger}$ Commentary on... Value-based healthcare in mental health services. See this issue. 
measures. However, a second wave of interest has brought an increasing appreciation that holistic outcomes measures (looking at multiple domains) can allow clinical teams to track and improve what is 'most meaningful' for patients. Invariably, this points towards improvement in an individual's quality of life and well-being. New holistic outcomes measures such as ReQoL and DIALOG+ (Baggaley 2020) have paved the way for true patient-reported outcome measures (PROMS) in mental healthcare. The trend is towards greater patient centricity, enhanced transparency of data and more sophisticated real-time analysis, which can help clinicians to deliver well-informed data-driven care.

\section{Value, safety and best practice}

The 'value' in value-based healthcare is also one of sustained improvements in safety. Benchmarking and the optimisation of best practice through the collection and transparent sharing of outcomes helps to maintain quality and standards. Again, as we have seen in the seminal work of Florence Nightingale, we have a historical exemplar in the form of the celebrated Boston surgeon Ernest Codman in 1911:

\footnotetext{
'[Codman] made a lifelong systematic effort to follow up each of his patients years after treatment and recorded the end results of their care. He recorded diagnostic and treatment errors and linked these errors to outcomes in order to make improvements [...] he admitted his errors in public and in print. They are described in the annual report of his hospital. Codman paid out of his own pocket to publish this report so that patients could judge for themselves the quality and outcome of care. He sent copies of his annual reports to major hospitals throughout the country challenging them to do the same.' (Neuhauser 2002)
}

Fast forward 84 years to the Bristol Royal Infirmary Inquiry (1995), which reviewed the extremely high death rate of babies undergoing heart surgery at the Bristol Royal Infirmary during the 1980s and early 1990s. The resulting inquiry, headed by Professor Ian Kennedy QC, estimated that approximately 35 babies died unnecessarily at Bristol between 1990 and 1995, despite clear outcomes pointing to a serious and systematic quality problem (Kennedy 2001). There was a lack of openness and rigour in analysing clinical results, which proved disastrous for patient care. Data were available, but unlike Codman a century before and Florence Nightingale a half century before that, nobody cared much to use these data at Bristol to improve care. Chapter 20 of the final report makes for sobering reading:

'At the time, however, there was a temptation for the clinicians to persuade themselves, even in the face of such evidence, that any poor outcome could quite plausibly be explained away. They could equally plausibly speak in terms of an expectation of improvement over time, notwithstanding the failure of Bristol's performance to improve in comparison with improvement reported in other units.' (Kennedy 2001: p. 248)

\section{Barriers to implementation of value-based healthcare}

Those familiar with embedding value-based healthcare will appreciate that implementing the approach can create significant challenges. Ensuring that valid and reliable outcome measures are selected and collected consistently and with enough frequency demands the application of systematic collection methods. In the modern healthcare setting this is invariably carried out using electronic patient record systems. However, such 'information technology' systems often have not been created to deal with either the collection or analysis of outcomes. Substantial modification is therefore often required. However, probably the greatest barrier to the successful implementation of outcomes is cultural. In the case of psychiatrists, surveys lamentably show that many simply do not think that outcome collection is helpful or they think that it creates too much of a burden (Gilbody 2002; Zimmerman 2008). Learning from the tragic infant deaths at Bristol means that clinicians must consider the very real quality improvement principles inherent in outcomes collection. We must not fall into the same myopic trap.

\section{Cost must not outweigh compassion}

In the modern value-based healthcare paradigm 'resources' are delineated as costs. 'Value' (to the American value school) is therefore conceptualised as an abstraction of the degree of meaningful improvement for the patient (outcomes) per unit of resource (cost). Sir Muir Gray (of the European school) has done much to broaden this concept using the 'triple value' framework (personal, allocative and technical value), with a more recent elaboration of a fourth dimension, 'societal value', to form 'quadruple value' (European Commission 2019).

Moreover, significant high-quality economic modelling work has been conducted in the past decade, with the result that 'methods based on sound economic concepts can provide transparent and potentially useful information on efficiency comparisons (Cylus 2016: p. 99). Probably unfairly, the historian, writer and essayist Thomas Carlyle noted in 1849 the perils of economics in what he termed the 'dismal science'. There is always a danger of subversion with any enterprise overemphasising measurement or cost control. It risks squeezing the humanity from the endeavour. Nightingale, Codman and Avedis Donabedian knew this all too 
well. Donabedian, probably the greatest healthcare systems thinker of the 20th century (and an individual of great humanity) noted the following:

\begin{abstract}
'Systems awareness and systems design are important for health professionals. But are not enough. They are enabling mechanisms only. It is the ethical dimension of individuals that is essential to systems success. Ultimately the secret of quality is love.' (Best 2004)
\end{abstract}

Donabedian reminds us that, ultimately, good medical care is about striving for the best results through compassion for others. Value-based healthcare will accrue its greatest leverage when it incorporates the latest technology, efficiency techniques and medical advances without losing the cumulative lessons of the great outcome innovators. These are the shoulders upon which the current state of the art rests. They compel us to be brave enough to recognise when our care may not be up to standard and to act on that information.

\section{Volumising value}

The true promise of value-based healthcare lies primarily not in the affluent 'developed' countries (although this is considerable), but in its powerful, and yet to be realised, extension to the poorest and most impoverished areas of the world. 'Volumising value' by creating better outcomes for the same or reduced resources has the potential to save and improve many lives across the globe. Low- and middle-income countries (LMICs) have made admirable strides in improving healthcare on the basis of increasing the volume and access of services delivered. However, recent data strongly suggest that although 'access' is an important consideration, 'quality' trumps this when considering the design of healthcare systems to decrease mortality and morbidity (Leapfrog to Value 2019). LMICs therefore have an opportunity to develop their nascent healthcare systems without the structural flaws inherent in Western systems, according to true value-based healthcare principles, measuring outcomes and using data analysis as drivers of quality for their services (instead of focusing mainly on inputs and volume) and creating a payment system that rewards 'value' to sustain improvements (Leapfrog to Value 2019).

The value-based initiative represents an inchoate but potentially powerful network of quality improvement information. The key is to use these analysed outcomes data to inform sequential levels of care. As so elegantly demonstrated by Nightingale and Donabedian, these levels begin with outcomes at the individual patient level. Aggregated outcomes data can then be used to inform how treatment approaches vary across teams, divisions and hospitals. Gray, Teisberg and Porter show us that this approach can be used at a national and international level. Approaches leading to better outcomes can help others to improve and, combined with a transparency of clinical technique, encourage the most effective innovations to be replicated. This approach does require consensus on which outcomes data should be used and there is still considerable work to be done on the harmonisation of national and international data-sharing and benchmarking. Notwithstanding these challenges, the International Consortium for Health Outcomes Measurement (2020) has achieved some advances in this area with the production of global 'standard sets'. 'Volumisation' must take place at an individual, system and national level. This is the fundamental, worldwide value proposition that binds the golden outcomes braid of Nightingale through Codman, to Donabedian and Gray, and on to Porter and Teisberg.

\section{Declaration of interest}

None.

An ICMJE form is in the supplementary material, available online at https://doi.org/10.1192/bja. 2020.29.

\section{References}

Baggaley MR (2020) Value-based healthcare in mental health services. BJPsych Advances, 26: this issue.

Best M, Neuhauser D (2004) Avedis Donabedian, father of quality assurance and poet. Quality and Safety in Healthcare, 13: 472-3.

Cylus J, Papanicolas I, Smith P (2016) Health System Efficiency: How to Make Measurement Matter for Policy and Management. European Observatory on Health Systems and Policies.

European Commission (2019) Defining 'Value' in 'Value-based Healthcare': Report of the Expert Panel on Effective Ways of Investing in Health (EXPH). Publications Office of the European Union.

Gilbody SM, House AO, Sheldon TA (2002) Psychiatrists in the UK do not use outcomes measures: national survey. British Journal of Psychiatry, 180: 101-3.

International Consortium for Health Outcomes Measurement (2020) Standard sets. ICHOM (https://www.ichom.org/standard-sets/).

Kennedy I (2001) The Report of the Public Inquiry into children's heart surgery at the Bristol Royal Infirmary 1984-1995: Learning from Bristol. TSO (The Stationery Office)

Leapfrog to Value (2019) How Nations Can Adopt Value-Based Care on the Path to Universal Health Coverage. Leapfrog to Value.

McGarry DD (trans \& ed) (2015) The Metalogicon of John of Salisbury, A Twelfth-Century Defence of the Verbal and Logical Arts of the Trivium. Book 3 (reprint of 1962 edition). Martino Fine Books.

Neuhauser D (2002) Ernest Amory Codman MD. Quality and Safety in Healthcare, 11: 104-5

Neuhauser D (2003) Florence Nightingale gets no respect: as a statistician that is. Quality and Safety in Healthcare, 12: 317.

Zimmerman M, McGlinchey JB (2008) Why don't psychiatrists use scales to measure outcome when treating depressed patients? Journal of Clinical Psychiatry, 69: 1916-9. 